Corrigendum

\title{
Corrigendum to "Naïve Bayesian Classifier for Selecting Good/Bad Projects during the Early Stage of International Construction Bidding Decisions"
}

\author{
Woosik Jang, ${ }^{1}$ Jung Ki Lee, ${ }^{1}$ Jaebum Lee, ${ }^{2}$ and Seung Heon Han ${ }^{1}$ \\ ${ }^{1}$ School of Civil and Environmental Engineering, Yonsei University, Seoul 120-749, Republic of Korea \\ ${ }^{2}$ Department of Civil and Infrastructure, Hyundai Engineering Co., Ltd., Seoul 140-2, Republic of Korea \\ Correspondence should be addressed to Seung Heon Han; shh6018@yonsei.ac.kr \\ Received 7 June 2016; Accepted 4 August 2016
}

Copyright (c) 2016 Woosik Jang et al. This is an open access article distributed under the Creative Commons Attribution License, which permits unrestricted use, distribution, and reproduction in any medium, provided the original work is properly cited.

In the article titled "Naïve Bayesian Classifier for Selecting Good/Bad Projects during the Early Stage of International Construction Bidding Decisions" [1], there was an error in the "Acknowledgments" section, which should be corrected as follows.

This research was supported by a grant (11HightechUrbanG05) from the High-Tech Urban Development Program (HUDP) funded by the Ministry of Land, Transport and Maritime Affairs of the Korean government.

\section{References}

[1] W. Jang, J. K. Lee, J. Lee, and S. H. Han, "Naïve bayesian classifier for selecting good/bad projects during the early stage of international construction bidding decisions," Mathematical Problems in Engineering, vol. 2015, Article ID 830781, 12 pages, 2015. 


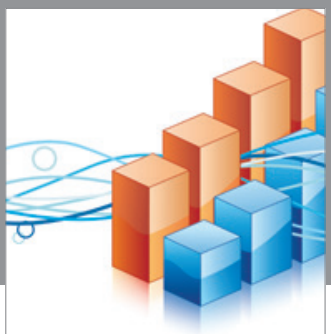

Advances in

Operations Research

vatem alat4

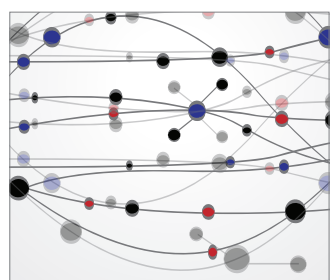

\section{The Scientific} World Journal
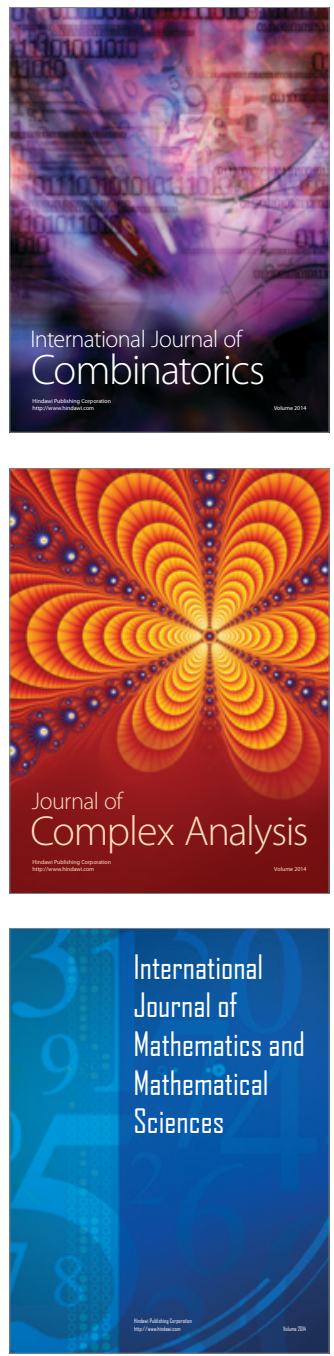
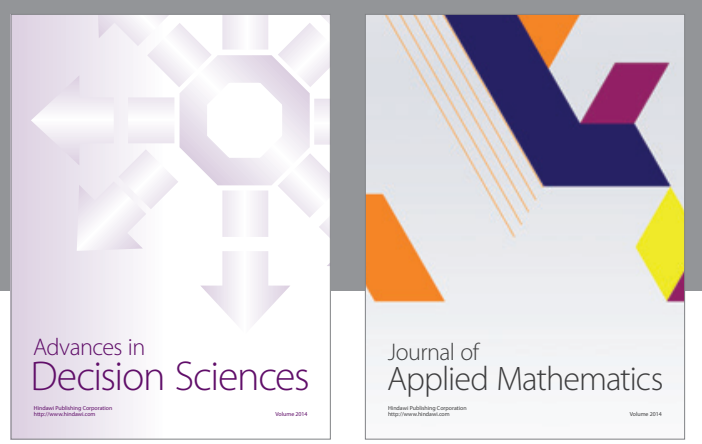

Algebra

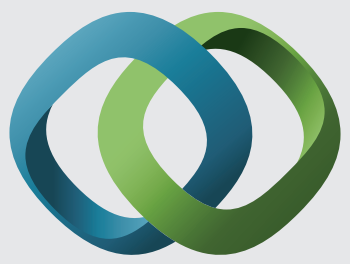

\section{Hindawi}

Submit your manuscripts at

http://www.hindawi.com
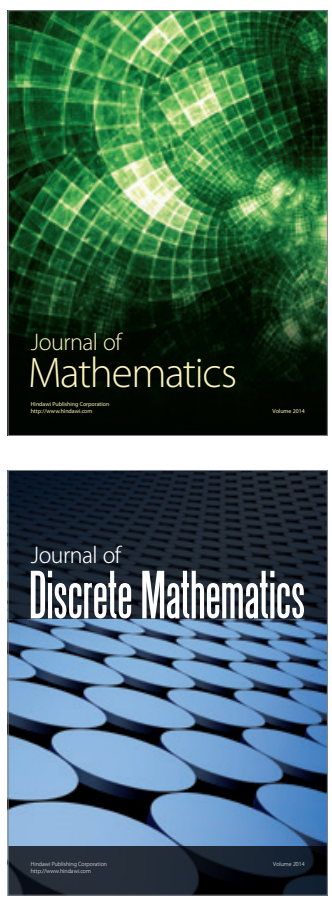

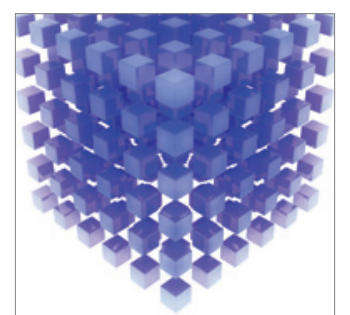

Mathematical Problems in Engineering
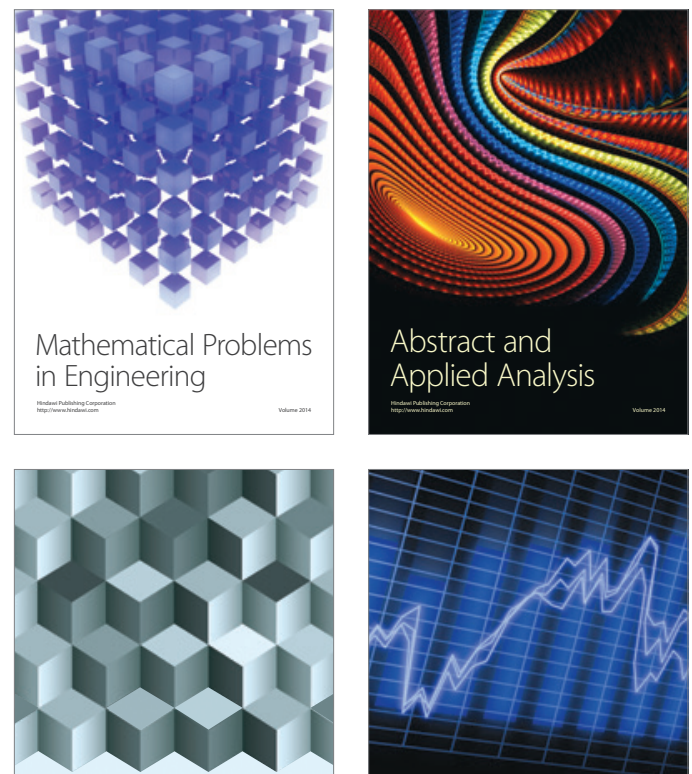

Journal of

Function Spaces

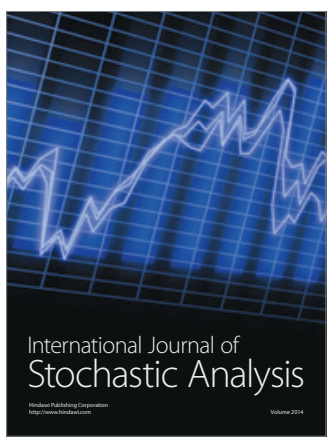

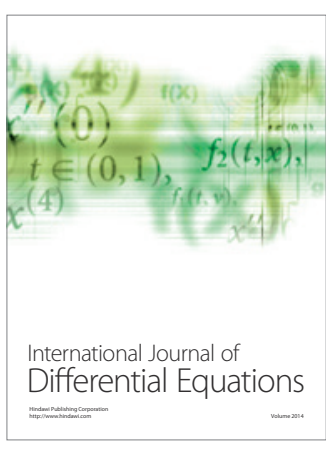
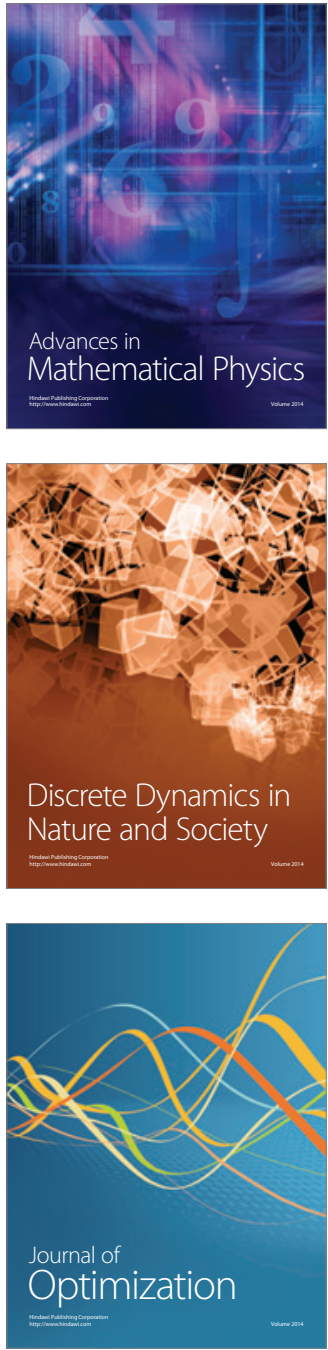